\title{
Basis of nocturnal polyuria in patients with autonomic failure
}

\author{
C. S. WILCOX, M. J. AMINOFF, AND W. PENN \\ From the Department of Neurological Studies, Middlesex Hospital Medical School, London, \\ and Department of Physiology, Charing Cross Hospital Medical School, London
}

SYNOPSIS Five dysautonomic patients with the Shy-Drager syndrome were studied to determine the basis of their nocturnal polyuria. The results indicated excessive postural modification of renal function in dysautonomic patients. This may, in fact, relate to excessive release of ADH while these patients are up and about, and excessive inhibition while they are recumbent. Treatment with vasopressin produced an inconsistent response.

Patients with autonomic failure have been observed to excrete excessive quantities of salt and water when recumbent at night (Bachman and Youmans, 1953; Shear, 1963). Low rates of aldosterone secretion have been found in some patients with orthostatic hypotension (Slaton and Biglieri, 1967; Aminoff and Wilcox, 1972) and may therefore contribute to the excessive sodium loss of recumbency. Whether or not the excessive water diuresis of recumbency is related to defective secretion of antidiuretic hormone (ADH) in these patients in unknown. Although $\mathrm{ADH}$ release is regulated in part by osmoreceptors, it is influenced also by less well-defined receptors related to intravascular volume and pressure (Share, 1969). Thus, in patients with autonomic failure and orthostatic hypotension, the large fluctuations in blood pressure which occur with change in posture could lead to excessive fluctuations in $\mathrm{ADH}$ secretion. We have therefore studied the effect of posture on the renal responses to water loads and deprivation in such patients. An acute rise in solute clearance on lying down will reduce the ability of ADH to concentrate the urine (Raisz et al., 1959) and thus the volume of the urine will not necessarily reflect the level of $\mathrm{ADH}$ activity. Hence, in this investigation the excretion of ADH was determined by bioassay.

Address for correspondence: Dr. M. J. Aminoff, Maida Vale Hospital, London, W9 1TL.

\section{METHODS}

PATIENTS The experimental group comprised five patients with the Shy-Drager syndrome (Shy and Drager, 1960) who have been described in detail elsewhere (Aminoff et al., 1973). They ranged in age from 48 to 68 years. They had clinical signs of widespread lesions in the motor nervous system, but Parkinsonism was the most conspicuous feature in all of them. All had gross autonomic dysfunction with impairment of cardiovascular reflex activity and a disturbance of pilomotor, sudomotor, and bladder function. For brevity, these patients will be referred to as dysautonomic. In all, the orthostatic hypotension was severe, the usual fall in mean blood pressure on standing being $25-40 \mathrm{mmHg}$. Mean creatinine clearances for these patients were: lying $95 \mathrm{ml}, \min ^{-1}$ (range 75-124), standing $62 \mathrm{ml}$, $\min ^{-1}$ (range 41-82).

The control group comprised five patients with uncomplicated Parkinson's disease and normal autonomic function, although for some tests only four patients were used. They ranged in age from 48 to 65 years. They were selected because they were similar to the dysautonomic patients in neurological disability, age, weight, and drug therapy. Mean creatinine clearances for these patients were: lying $82 \mathrm{ml}, \mathrm{min}^{-1}$ (range 56-108), standing $75 \mathrm{ml}$, $\min ^{-1}$ (range 53-92). Both the dysautonomic and the control patients with Parkinsonism were in hospital; all were receiving conventional anticholinergic drugs for their Parkinsonism, but none was taking levodopa. They all received a normal ward diet, and random 24 hour urine samples in these patients contained an average of $113 \mathrm{mEq}$ 

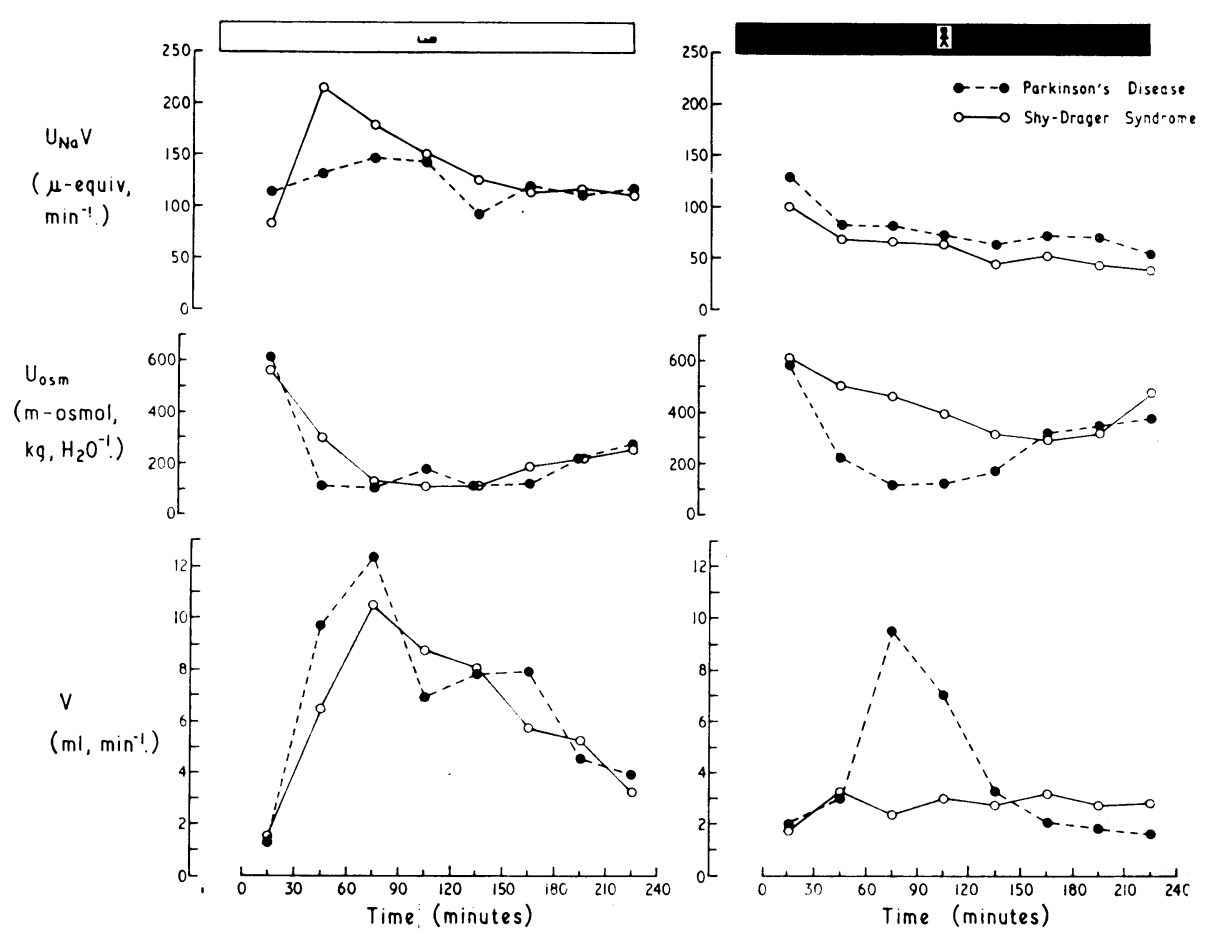

FIG. 1. Variation in the renal responses to a water load when lying ( $\square$ ) or standing ( $\square$ ). Five dysautonomic patients and four control subjects were studied. They received water loads of $20 \mathrm{ml}$ $\mathrm{kg}^{-1}$ at 9 a.m. Urine samples were individually analysed and the averaged results are presented for urine passed during successive 30 minute periods over the four hours after ingestion of the load.

sodium (range 46-195) and $43 \mathrm{mEq}$ potassium (range 22-66).

Hypokalaemia, hypercalciuria, and glycosuria were excluded in all patients by the appropriate blood and urine tests.

Informed consent was obtained from all participants.

WATER LOADS Five dysautonomic patients and four control subjects were studied. After a light breakfast, each subject emptied his bladder and took the water load of $20 \mathrm{ml} \mathrm{kg}{ }^{-1}$ at 9 a.m. After drinking the water, urine was collected for analysis every 30 minutes for four hours. The test was performed on two occasions for each subject. On one occasion the subjects were standing during the test, while during the other they were recumbent except when micturating. The order of the procedures was randomized.

WATER DEPRIVATION Five dysautonomic patients and four control subjects were deprived of fluids for 36 hours, commencing at 6 p.m. They were allowed a dry ward diet from which soups, jellies, and other fluid foods were excluded. Urine was collected for analysis over four hourly periods. Patients remained in bed from 10 p.m. till 6 a.m. except to micturate. For the remainder of the day they were up and about the ward taking part in their usual activities. They were allowed to sit but not to lie down.

Patients refrained from smoking or taking alcohol over the period of the study. Except where stated, meals were taken at the customary times (8 a.m., 12 noon, 4 p.m., and 7 p.m.). Five or $10 \mathrm{ml}$ of fluid were allowed to help swallow drugs.

BIOASSAY The concentration of ADH in urine was estimated by the bioassay method described pre- N viously (Forsling et al., 1968). Fresh urine was acidified to pH 5 with $0 \cdot 1 \mathrm{~N}$ hydrochloric acid and frozen. Duplicate analyses were subsequently performed on the concentrated urine extract by a 2 worker who was unaware of the origin of the sample. 


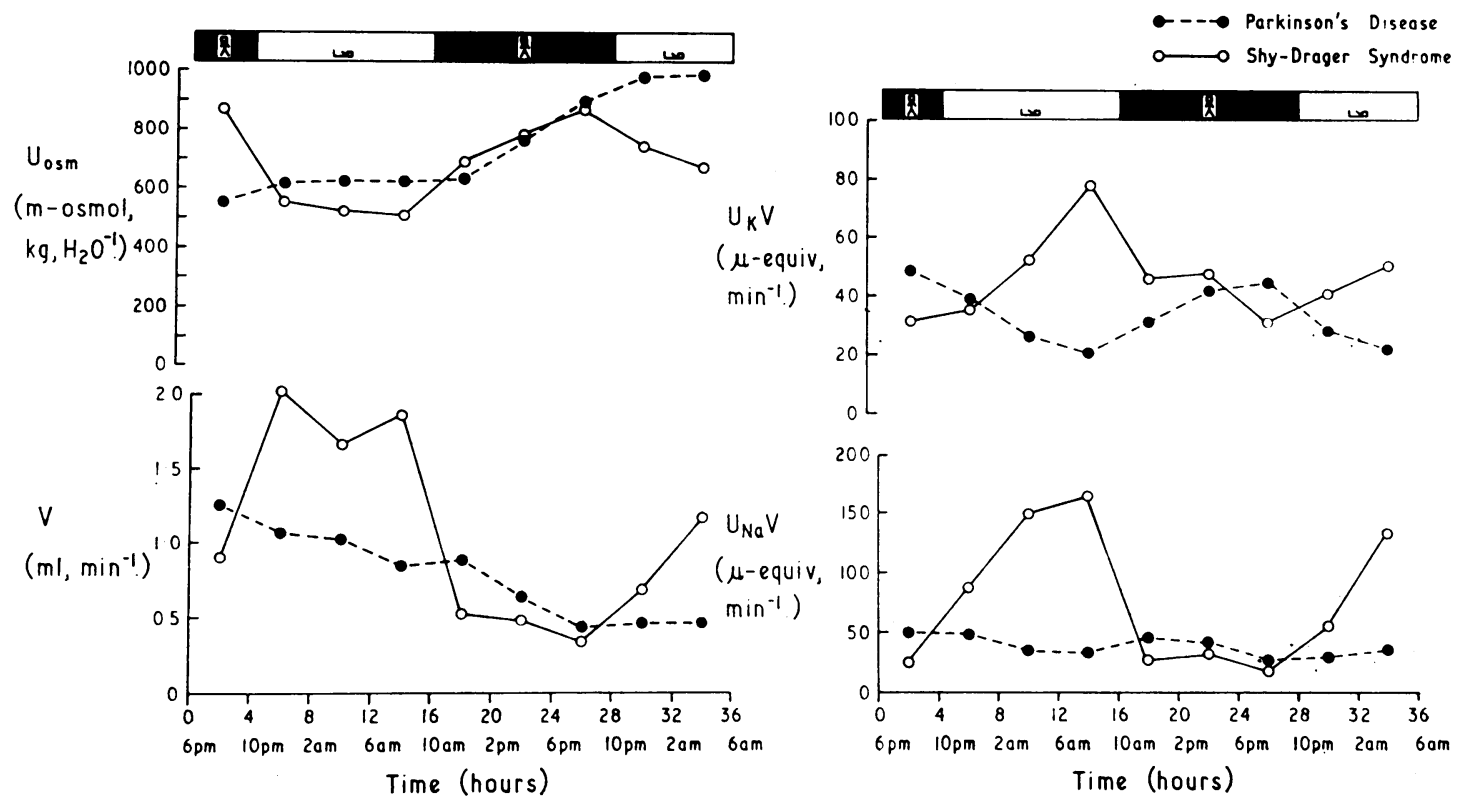

FIG. 2. The renal responses of five dysautonomic patients and four control subjects to fluid deprivation for 36 hours, commencing at 6 p.m. Average results are presented of urine osmolality and volume, and potassium and sodium excretion for each successive four hour period. Subjects were lying down ( $\square)$ during the night (10 p.m. to 10 a.m.) and up and about (ם) during the day (10 a.m. to 10 p.m.).

GENERAL Sodium and potassium concentrations in urine and plasma were measured in an EEL flame photometer. Osmolalities were measured cryoscopically in an Advanced Osmometer. Plasma cortisol was measured as fluorimetric corticosteroids by the method of Mattingly (1962).

The statistical significance of the results obtained was calculated by Student's $t$ test.

A trial of treatment with synthetic lysine vasopressin nasal spray (Syntopressin) was undertaken in four dysautonomic patients.

\section{RESULTS}

WATER LOAD The mean values for the renal response to the water load are shown in Fig. 1. When recumbent, all subjects had a considerable rise in urine volume and fall in osmolality. Mean sodium excretion over the first 120 minutes rose slightly in the controls, but in dysautonomic patients there was a sharp increase reaching a maximum within 60 minutes followed by a progressive decline.

When standing, a diuresis was observed in all control subjects, although the onset of the diuresis was slightly reduced and delayed. Their fall in urinary osmolality was comparable with recumbency. In contrast, dysautonomic patients had no diuresis in response to the water load when they were standing. Their mean decrease in urinary osmolality did not fall below the assumed plasma value of about 280 m-osmol. Sodium excretion declined progressively in both groups. This failure to attain a water diuresis when standing is well exemplified by one dysautonomic subject whose urinary osmolality did not fall below 375 m-osmol during the four hours of the study. However, approximately 18 hours later, when recumbent in bed at night, he had a considerable diuresis and the urinary osmolality was reduced to $120 \mathrm{~m}$-osmol.

WATER DEPRIVATION The 36 hours of fluid deprivation caused a weight loss of between $2 \cdot 0$ and $3.3 \%$ of body weight in the three control subjects in whom weight was recorded.

In control subjects, urine volume fell and osmolality increased progressively during the 36 hours of water deprivation (Fig. 2). Sodium 


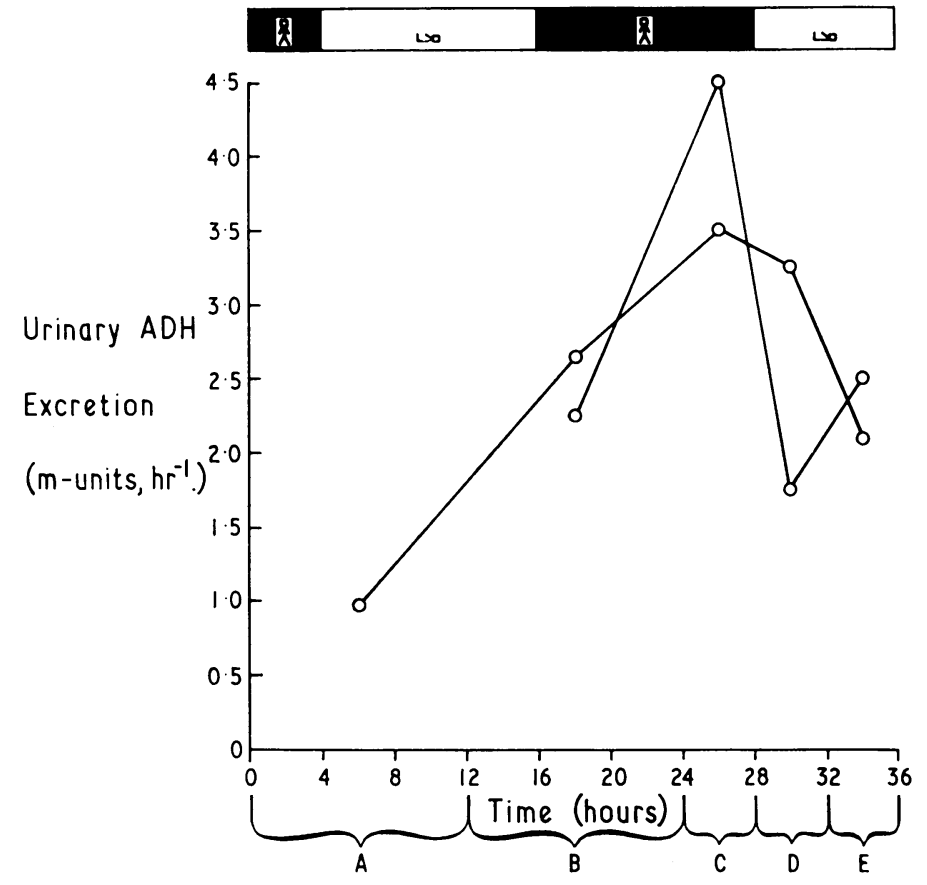

FIG. 3. Renal excretion of $A D H$ in two dysautonomic patients deprived of fluid for 36 hours. Subjects were lying down $(\square)$ during the night (10 p.m. to 10 a.m.) and up and about $(\square)$ during the day (10 a.m. to 10 p.m.). The five urine collection periods are marked $\mathrm{A}$ to $\mathrm{E}$ at the bottom of the Figure. Note that the first two, $\mathrm{A}$ and $\mathrm{B}$, relate to periods in which subjects were up and about for part of the time and recumbent at other times. This is followed by $\mathrm{C}$ during which the subjects were up and about at the end of the day. There follow $\mathrm{D}$ and $\mathrm{E}$ during which the subjects were lying down in bed at night.

excretion remained unchanged but potassium excretion was greater during the day than during the night.

Similar changes in sodium and potassium excretion, and in urine volume and urine osmolality were seen in dysautonomic and control subjects during the daytime. However, during the two nocturnal periods when the subjects were lying down, the dysautonomic patients had considerable increases in sodium and potassium excretion and urine volume, while urinary osmolality decreased. Thus, the dysautonomic patients had abnormalities of water and electrolyte excretion during dehydration only while they were recumbent at night.

ADH excretion was measured in two dysautonomic subjects during dehydration (Fig. 3). Over the first 24 hours, urine was collected in periods during which the patients were both lying down and standing or sitting, and $\mathrm{ADH}$ excretion was seen to rise. During the period 24 to 28 hours (6 p.m. to 10 p.m.) the patients were standing or sitting, and $\mathrm{ADH}$ excretion reached its highest values $\left(3.5\right.$ and $4.5 \mathrm{~m}$-units, $\left.\mathrm{hr}^{-1}\right)$ in both subjects. Two subsequent collections were made (10 p.m. to 2 a.m., 2 a.m. to 6 a.m.) while the patients were in bed at night. Despite the cons tinuing dehydration, ADH excretion fell in bot at the end of dehydration to $2 \cdot 1$ and $2.4 \mathrm{~m}$-units $\mathrm{hr}^{-1}$.

UNRESTRICTED FLUID Water and ADH excretion were studied in one dysautonomic patient during unrestricted fluid intake (Fig. 4). A pattern similar to that observed during dehydration was evident. Urine volume increased at night and this was accompanied by a fall in osmolality and ADH excretion. Sodium and potassium excretion were again noted to rise at night.

A qualitative assessment was made of the response of the noctural polyuria in four dysautonomic patients to lysine-vasopressin administered alone by nasal spray at night. All reported an initial reduction in nocturnal urine volume, but there was often a relapse after some weeks of treatment. An attempt was made to assess the renal responses to soluble vasopressin given in graded doses up to 2 units, injected intramuscularly at 6 a.m. and 10 p.m. However, this had to be abandoned because the resulting pressor response, due to supersensitivity in the 


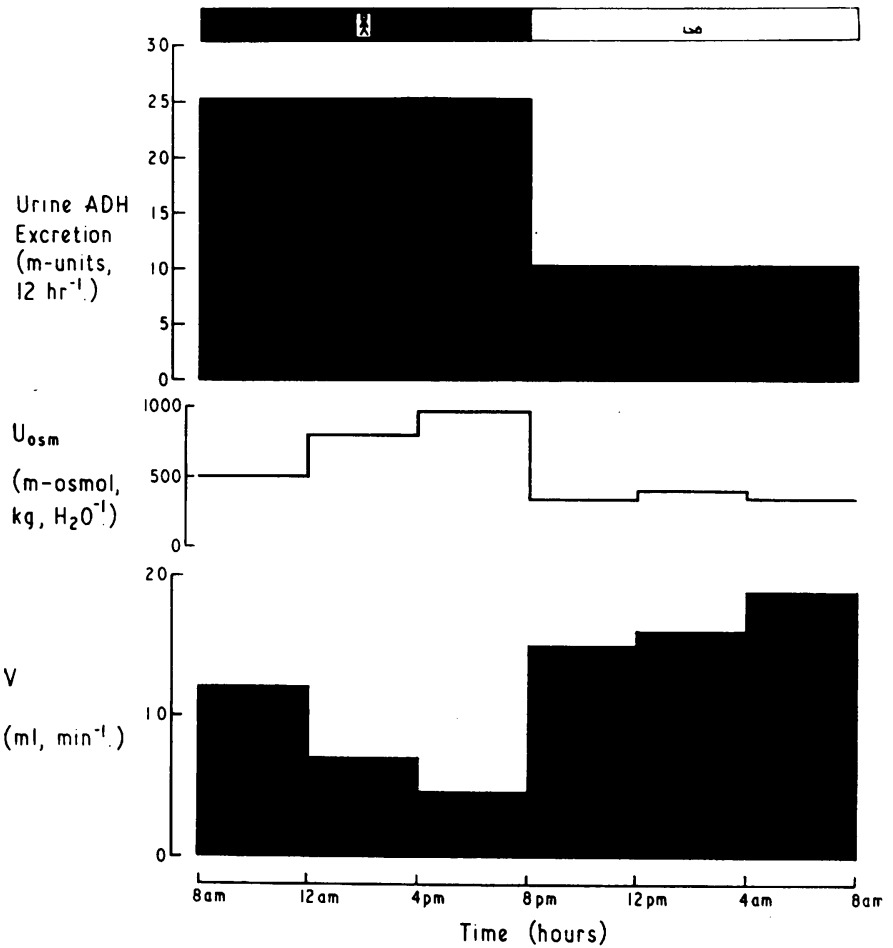

FIG. 4. Excretory rhythms during unrestricted fluid intake in a dysautonomic patient. The patient was up and about $(\square)$ for 12 hours during the day and recumbent $(\square)$ in bed during the 12 hours of night. Mean values for urine volume and osmolality are shown for successive four hour periods over six days. $A D H$ excretion was measured during one night and one day period of 12 hours each.

dysautonomic patients, made interpretation impossible. Such pressor responses were not observed when up to 20 units of synthetic lysinevasopressin was taken by nasal spray, presumably because only a small part reached the circulation when given by this route.

DIURNAL RHYTHM IN PLASMA CORTISOL The normal decline in plasma cortisol from morning to evening was maintained in the five dysautonomic patients. Neither morning nor evening values were significantly different from the five patients with Parkinson's disease. Mean values for plasma cortisol $\left(\mu \mathrm{g}, 100 \mathrm{ml}^{-1}\right)$ in the morning were $\mathbf{1 3 . 9}$ for the five patients in both groups. In the evening, the mean value was 7.5 in the dysautonomic patients and 8.6 in the patients with Parkinson's disease.

\section{DISCUSSION}

Verney (1946) proposed that changes in renal function during water loading were due primarily to an inhibition of $\mathrm{ADH}$ release. The diuresis in the control subjects (Fig. 1). corresponded to that previously described in normal subjects (Metzger et al., 1969). On standing they all had a diuresis, although the onset was slightly reduced and delayed compared with that of recumbency, due probably to higher pre-existing levels of ADH (Segar and Moore, 1968). During recumbency the dysautonomic patients had a diuresis similar to that of the control subjects. On standing, however, there was no diuresis after the water load. Although urine osmolality fell, the mean value did not pass below the assumed plasma value of about $280 \mathrm{~m}$-osmol. This inability to dilute the urine when upright suggests that standing is a potent stimulus to $\mathrm{ADH}$ release which even the plasma hypotonicity produced by drinking water is unable to inhibit fully.

The control subjects responded normally to water deprivation (McCance and Young, 1944) by a progressive fall in urine volume and a rise in urine osmolality which was maximal after about 24 hours (Fig. 2). When the dysautonomic patients were up and about, dehydration produced a normal decrease in urine volume and an 
increase in urine osmolality. In contrast, during recumbency urine volume increased considerably and osmolality actually fell despite the continuing dehydration. While up and about, ADH excretion by the two dysautonomic patients studied also rose progressively to reach values of 3.5 and 4.5 m-units, $\mathrm{hr}^{-1}$ after 24 hours of dehydration (Fig. 3). This was within the range found for normal subjects after this period of water deprivation (Lee, 1963). However, ADH excretion then declined by about $50 \%$ in these dysautonomic patients while they were recumbent at night during the 28-36 hour period of dehydration, whereas in normal subjects a further considerable increase occurred (Lee, 1963). Thus these two dysautonomic patients were able to increase $\mathrm{ADH}$ excretion during dehydration, but this response was markedly influenced by change in posture.

When dysautonomic patients changed from standing to lying, the accompanying increase in glomerular filtration rate (GFR) that was observed should increase ADH excretion if the blood level remained constant (Dicker, 1970). Therefore, the fall in ADH excretion that we observed in the present study when the dysautonomic patients lay down may have underestimated the true fall in blood level of ADH at this time. Thus the data indicate that in dysautonomic patients lying produces a potent inhibition of ADH release which even progressive dehydration cannot overcome fully.

During water deprivation, the control subjects showed an increase in potassium excretion during the daytime, in agreement with previous reports (Vagnucci et al., 1969), although no marked change in sodium excretion was apparent. However, the dysautonomic patients showed a reversal of the normal rhythm of electrolyte excretion, with sodium and potassium excretion rising during the night. The increase in glomerular filtration rate of these dysautonomic patients at night may have contributed to the increased electrolyte excretion at this time.

As posture-dependent differences in salt and water excretion were seen in dysautonomic patients after water loads given at the same time of day, the results indicate that the variation is determined primarily by posture rather than by a reversal of circadian rhythm. Moreover, there was a normal circadian rhythm for plasma cortisol in our patients. An attempt to analyse further this aspect by keeping the patients in bed during the day had to be abandoned as it produced a deterioration in their clinical state.

The same excessive diurnal fluctuation in the excretion of water and ADH was found in a $\subseteq$ patient on an uncontrolled fluid intake (Fig. 4). ADH excretion does not usually exceed 30 m-units, day ${ }^{-1}$ in normal subjects at rest and on a free fluid intake (Lee, personal communication), but it was 35 m-units, day ${ }^{-1}$ in our dysautonomic patient. This raised excretion occurred only during the daytime (Fig. 4), thereby confirming Wagner's (1959) suggestion के that, in patients with orthostatic hypotension, $\mathrm{ADH}$ release is excessive when standing. In contrast, the diurnal variation of $\mathrm{ADH}$ excretion in normal subjects is slight and inconsistent (Goldman and Luchsinger, 1956; Goodwin et al., 긍 1968).

Four dysautonomic patients received vasoD pressin by nasal spray at night. Although tho nocturnal polyuria was diminished initially in å subjects, the response became irregular or abser after some weeks of treatment. A similar diminu ㅏㅜ tion in sensitivity to vasopressin has been foun 8 in normal subjects during prolonged vasopress administration, and has been attributed to ove hydration (Jaenicke and Waterhouse, 1961).

From our investigation, there is evidence that alteration of $\mathrm{ADH}$ secretion may in part be responsible for the observed abnormal changes in urine volume with change in posture of dysautonomic patients. However, further work is required to ascertain the part played by denervation of the kidneys and the precise influence of hormones in this disease. In animals, hypovolaemia has been shown to be capable of stimulating ADH release, despite plasma hypotonicity (Arndt and Gauer, 1963). Likewise, $\dot{0}$ hypervolaemia can inhibit ADH release despite plasma hypertonicity (Share 1962; Zehr et al., ᄋ 1969). The 'volume receptors' that are responsible are believed to be located both in the arterial 응 and in the 'low-pressure' vascular systems (Share, $>$ 1969). Similar receptors may initiate the correc-을 tive alterations in sodium excretion that follow $N$ alteration in blood volume (Gauer et al., 1970). N Patients with autonomic failure respond to a N change in blood volume or posture with exaggerated changes in cardiac output, mean arterial 
pressure, and pulse pressure, since they lack the normal reflex compensatory mechanisms (Hickam and Pryor, 1951; Wagner, 1957). These exaggerated cardiovascular changes may induce marked afferent stimulation or inhibition from the 'volume receptors', which may then monitor renal function.

\section{SUMMARY}

Five dysautonomic patients with the ShyDrager syndrome were studied to determine the basis of their nocturnal polyuria. Five patients with Parkinson's disease comprised the control group. Patients were given a water load of $20 \mathrm{ml} \mathrm{kg} \mathrm{kg}^{-1}$ body weight at a predetermined time during the day. Studies were performed with patients recumbent on one occasion and standing on another. In the dysautonomic patients, standing markedly inhibited the water diuresis. During a 36 hour period of fluid deprivation, urinary volume increased and osmolality decreased in the dysautonomic patients when they were recumbent at night. Urinary excretion of sodium and potassium also increased at this time. During unrestricted fluid intake similar changes in urinary volume, in electrolyte excretion and in osmolality also occurred in these recumbent patients. Antidiuretic hormone (ADH) excretion was estimated in three dysautonomic patients. Both during free fluid intake (one subject) and during fluid deprivation (two subjects) $\mathrm{ADH}$ excretion fell at night while they were recumbent. Four dysautonomic patients were treated with vasopressin given by nasal spray at night. They reported an initial reduction in nocturnal polyuria, but the response became inconsistent after some weeks.

The results indicate excessive postural modification of renal function in dysautonomic patients. This may in part relate to excessive ADH release while these patients are up and about, and excessive inhibition of $\mathrm{ADH}$ release while they are recumbent.

We are grateful to Dr. M. Kremer for allowing us to study patients under his care. It is a pleasure to record our gratitude also to Professor J. Lee, in whose laboratory the ADH estimations were performed, for his helpful advice; to Dr. F. S. Nashat and Dr. J. D. H. Slater for advice and discussion; to Dr. J. Keenan and the staff of the Courtauld Institute of Biochemistry for help with the biochemical estimations; and to Miss Wong and the department of medical illustration for preparation of the Figures.

\section{REFERENCES}

Aminoff, M. J., and Wilcox, C. S. (1972). Control of blood pressure in Parkinsonism. Proceedings of the Royal Society of Medicine, 65, 944-946.

Aminoff, M. J., Wilcox, C. S., Woakes, M. M., and Kremer, M. (1973). Levodopa therapy for Parkinsonism in the Shy-Drager syndrome. Journal of Neurology, Neurosurgery, and Psychiatry, 36, 350-353.

Arndt, J. O., and Gauer, O. H. (1963). Die Diurese infolge Wasserinfusion in die Carotisschlinge des wachen Hundes und ihre Beeinflussung durch kleine Aderlässe. (Abstract.) Pflügers Archiv für die Gesamte Physiologie, 278, 51-52.

Bachman, D. M., and Youmans, W. B. (1953). Effects of posture on renal excretion of sodium and chloride in orthostatic hypotension. Circulation, 7, 413-421.

Dicker, S. E. (1970). Mechanisms of Urine Concentration and Dilution in Mammals, pp. 112-113. Monographs of the Physiological Society No. 20. Arnold: London.

Forsling, M. L., Jones, J. J., and Lee, J. (1968). Factors affecting the sensitivity of the rat to vasopressin. Journal of Physiology, 196, 495-505.

Gauer, O. H., Henry, J. P., and Behn, C. (1970). The regulation of extracellular fluid volume. Annual Review of Physiology, 32, 547-595.

Goldman, R., and Luchsinger, E. B. (1956). Relationship between diurnal variations in urinary volume and the excretion of antidiuretic substance. Journal of Clinical Endocrinology and Metabolism, 16, 28-34.

Goodwin, J. C., Jenner, F. A., and Slater, S. E. (1968). The diurnal pattern of excretion of antidiuretic hormone. Journal of Physiology, 196, 112-113P.

Hickam, J. B., and Pryor, W. W. (1951). Cardiac output in postural hypotension. Journal of Clinical Investigation, 30, 401-405.

Jaenike, J. R., and Waterhouse, C. (1961). The renal response to sustained administration of vasopressin and water in man. Journal of Clinical Endocrinology and Metabolism, 21, 231-242.

Lee, J. (1963). The estimation of vasopressin in the blood and urine of hydrated and dehydrated subjects. Journal of Physiology, 167, 256-262.

McCance, R. A., Young, W. F., and Black, D. A. K. (1944). The secretion of urine during dehydration and rehydration. Journal of Physiology, 102, 415-428.

Mattingly, D. (1962). A simple fluorimetric method for the estimation of free 11-hydroxycorticoids in human plasma. Journal of Clinical Pathology, 15, 374-379.

Metzger, R. A., Vaamonde, L. S., Vaamonde, C. A., and Papper, S. (1969). Renal excretion of sodium during oral water loading in man. Nephron, 6, 11-27.

Raisz, L. G., Au, W. Y. W., and Scheer, R. L. (1959). Studies on the renal concentrating mechanism. IV. Osmotic diuresis. Journal of Clinical Investigation, 38, 1725-1732.

Segar, W. E., and Moore, W. W. (1968). The regulation of antidiuretic hormone release in man. 1. Effects of change in position and ambient temperature on blood ADH levels. Journal of Clinical Investigation, 47, 2143-2151.

Share, L. (1962). Vascular volume and blood level of antidiuretic hormone. American Journal of Physiology, 202, 791-794.

Share, L. (1969). Extracellular fluid volume and vasopressin secretion. In Frontiers in Neuroendocrinology, pp. 183-210. Edited by W. F. Ganong and L. Martini. Oxford University Press: New York. 
Shear, L. (1963). Renal function and sodium metabolism in idiopathic orthostatic hypertension. New England Journal of Medicine, 268, 347-352.

Shy, G. M., and Drager, G. A. (1960). A neurological syndrome associated with orthostatic hypotension. Archives of Neurology (Chic.), 2, 511-527.

Slaton, P. E., Jr., and Biglieri, E. G. (1967). Reduced aldosterone excretion in patients with autonomic insufficiency. Journal of Clinical Endocrinology and Metabolism, 27, 3745.

Vagnucci, A. H., Shapiro, A. P., and McDonald, R. H., Jr. (1969). Effects of upright posture on renal electrolyte cycles. Journal of Applied Physiology, 26, 720-731.
Verney, E. B. (1946). Absorption and excretion of water. The antidiuretic hormone. Lancet, 2, 739-744.

Wagner, H. N., Jr. (1957). The influence of autonomic vasoregulatory reflexes on the rate of sodium and water excretion in man. Journal of Clinical Investigation, 36, 1319-1327.

Wagner, H. N., Jr. (1959). Orthostatic hypotension. Bulletin of the Johns Hopkins Hospital, 105, 322-359.

Zehr, J. E., Johnson, J. A., and Moore, W. W. (1969). Left atrial pressure, plasma osmolality, and ADH levels in the unanesthetized ewe. American Journal of Physiology, 217, $1672-1680$. 